Çukurova Üniversitesi Mühendislik Mimarlık Fakültesi Dergisi, 30(1), 183-196 ss., Haziran 2015

Çukurova University Journal of the Faculty of Engineering and Architecture, 30(1), pp. 183-196, June 2015

\title{
Tarımsal Uygulamalarda Kullanılan Tekstil Ürünleri
}

\author{
İlhami ÍLHAN*1 \\ ${ }^{1}$ Çukurova Üniversitesi, Mühendislik Mimarlık Fakültesi, Tekstil Mühendisliği Bölümü, \\ Adana
}

Geliş tarihi: 15.04 .2015

Kabul tarihi: 17.06 .2015

\section{Özet}

Gelecekte gittikçe daha fazla önem kazanması beklenen tarım sektöründe, teknik tekstillerin bir alt dalı olarak tarım tekstilleri kullanımı gittikçe yaygınlaşmaktadır. Tarım tekstillerinin başlıca kullanım amacı; tarımsal üretim verimliliğini ve ürün kalitesini artırmaktır. Bu çalışma kapsamında, tarım sektöründe kullanılan tekstil ürünleri araştırılmıştır. Tarım tekstillerinin bugünkü durumu ve geleceği incelenmiştir. Tarım tekstillerinin kullanım alanları incelenmiş, ekolojik açıdan değerlendirmesi yapılmış, geleceğe dönük beklenen gelişmeler vurgulanmıştır. Tarım tekstilleri ve kullanım alanı çeşitliliğinin çok fazla olduğu, gelecekte daha da artabileceği belirlenmiştir. Göze çarpan başlıca gelişmelerin, tarım tekstilleri üretiminde nanoteknolojinin ve doğada çözünür polimerlerin kullanımı olacağı öngörülmektedir.

Anahtar Kelimeler: Tekstil, Tarım, Tarım tekstilleri, Teknoloji

\section{Textile Products Used in Agricultural Applications}

\begin{abstract}
In the agricultural sector that expected to be gradually more important in the future, the use of agro textiles as a sub-branch of technical textiles are becoming increasingly widespread. The main purpose of agrotextiles is to increase the production efficiency and product quality. In this study, the textile products used in agriculture were reviewed. The current status and future of agricultural textiles were investigated. Agrotextiles were assessed ecologically as well as for agricultural uses and the expected developments in the future were emphasised. It is determined that the diversity of agricultural textiles and their usage areas are too much and could further increase in the future. It is expected that the notable major developments are going to be the nanotechnology applications and biodegradable polymer usage in production of agrotextiles.
\end{abstract}

Keywords: Textile, Agriculture, Agrotextiles, Technology

\footnotetext{
* Yazışmaların yapılacağı yazar: İlhami İLHAN, Mühendislik Mimarlık Fakültesi, Tekstil Mühendisliği Bölümü, Adana.iilhan@cu.edu.tr
} 


\section{GİRIŞ}

Gelecekte tüm dünyanın en önemli sorununun beslenme sorunu olacağı ve besin maddesi üretiminde kendine yeterli olup, aynı zamanda dış satım yapabilecek üretim fazlasına sahip ülkelerin, sanayileşmelerini de geliştirerek planlı ve programlı bir yol izleyebilirlerse, dünya ekonomisinde söz sahibi olabilecekleri öngörülmektedir. Tarım sektöründe arz fazlalığ egemen bir dönemden arz açığı egemen bir döneme geçilmesi, küresel ısınmanın neden olduğu iklim değişiklikleri, tatlı su kıtlığı, ekolojik üretimin gerekliliği gibi nedenler, tarımda üretimi ve verimliliği daha önemli hale getirmektedir. Son yıllarda kişi başına düşen tarım arazisinin gelişmiş ülkelerde $\% 14,3$ oranında, gelişmekte olan ülkelerde ise $\% 40$ oranında azaldığı bildirilmiştir. Günümüzde dünya ölçeğinde kişi başına düşen tarım arazisi 0,23 hektar olup, 2050 yılında bu miktarın 0,15 hektar'a kadar düşmesi ve 2020 yılına kadar gida fiyatlarının \% 15-40 civarında artması beklenmektedir [1,2].

$\mathrm{Bu}$ bağlamda, tarım sektöründeki gelişmelere koşut olarak, tarımda kullanılan tekstil ürünlerinde de teknolojik gelişmeler ve nicelik artışı beklenmelidir. Tarım tekstilleri adıyla anılan bu tür tekstil ürünleri, teknik tekstillerin bir alt sınıfı olup, estetik ve görsel özelliklerinden çok teknik performansları ve işlevsel özellikleri nedeniyle üretilen tekstil malzemeleridir. Tarım tekstilleri; tarım, bahçe bitkileri (çiçekçilik dâhil), su ürünleri ve ormancılık gereksinimleri için üretilen teknik tekstil malzemelerini kapsamaktadır [3]. Son yıllarda tarım tekstillerini de kapsayan teknik tekstillerin küresel tekstil pazarı içindeki payı \%18,7 civarında olup, 2014-2019 yılları arasında yıllık ortalama \%3,71 oranında büyüyeceği tahmin edilmektedir [4,5]. Şekil 1'de tarım tekstilleri üretiminin dünya ölçeğinde yıllara göre değişimini gösteren bir grafik sunulmuştur. 2011 yilında küresel olarak tarım tekstillerinin teknik tekstiller içindeki payı \%4,2 olarak gerçekleşmiştir. Dünya ölçeğinde, tarım tekstilleri tüketimi artış hızının ortalama \%3-4 civarında olduğu tahmin edilmektedir [6,7]. Hindistan gibi tarım sektörü güçlü olan bazı ülkelerin tarım tekstilleri üretimi ve tüketimi konusunda plânlı bir politika izledikleri anlaşılmaktadır.

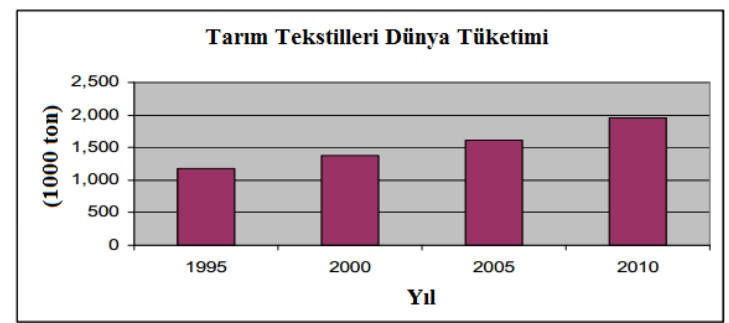

Şekil 1. Yıllara göre tarım tekstilleri dünya tüketim miktarı [8]

Tarım tekstillerinin kendi içindeki pazar payı dağılımı konusunda düzenli istatistik verilere ulaşma güçlüğü nedeniyle, fikir vermesi açısından Şekil 2'de Hindistan'a ait veriler paylaşılmıştır. Her ne kadar ülkelere göre değişim gösterse de, toplam tüketim içindeki payı en fazla olan tarım tekstili ürünü balık ağları olduğu söylenebilir. Onun ardından sırasıyla yer örtüleri (malç), gölgeleme fileleri ve dolu/kuş fileleri gelmektedir [9].

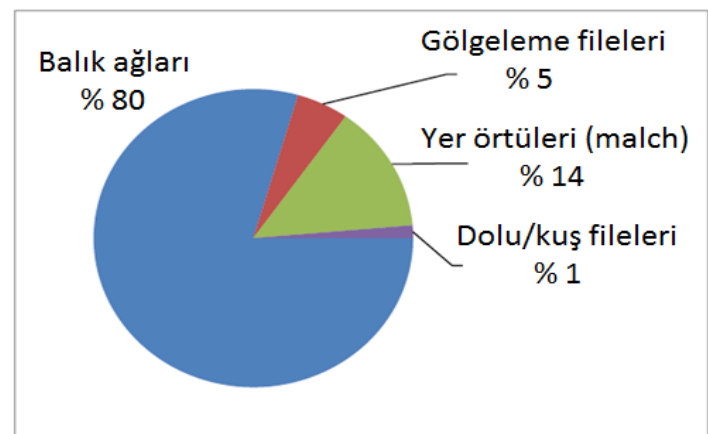

Şekil 2. Hindistan'da tarım tekstilleri pazar payı dağılımı (2012-13) [9]

Tarım teknik tekstilleri ülkemiz için, tarım sektörünün süregelen sorunlarından biri olan hasat öncesi ve sonrası ürün kayıplarının en aza indirgenmesi, üretimde verimliliğin arttırılması, maliyetlerin düşürülmesi açısından önemli bir potansiyel arz etmektedir. Ayrica, tarım tekstillerinin kullanımı, tarım ürünlerinde kalite ve üretim verimliliği artışına da katkı sağlayacaktır. $\mathrm{Bu}$ bağlamda, ülkemizde tarımsal üretim yapan 
firmaların/çiftçilerin tarım teknik tekstilleri konusunda bilinçlendirilmesi gerekmektedir [10].

\section{TARIM TEKSTILLERI VE BAŞLICA UYGULAMA ALANLARI}

Tarım tekstillerinin ilk kullanımı 1948 yılında ABD'de küçük seraların ince saydam kağıt tabakalar (cellophane) ile kaplanması ile gündeme gelmiş, hemen ardından Japonya'da aynı amaçla PVC tabakalar kullanılmaya başlanmıştır. Zamanla kullanılan malzeme ve uygulama alanı çeşitliliği artarak diğer ülkelere yayılmıştır [11]. Tarım tekstillerinin uygulama alanı bulduğu bölgeler olarak, Avrupa'da Akdeniz kıyısındaki ülkeler, Hindistan, Çin ve Güney Amerika öne çıkmaktadır.

Tarım tekstilleri; tarımsal faaliyetlerde toprağın kurumasını önlemek, güneş 1şığının etkisini ayarlamak, enerji tasarrufu sağlamak, ürün güvenliğini arttırmak, ürünün lekelenmesini önlemek, renk düzenliliği sağlamak, tarım ilacı kullanımını azaltmak, çiftçiyi zararlı tarım ilaçlarından korumak, kaliteyi ve verimliliği iyileştirmek, bunların sonucu olarak pazardaki rekabet gücünü yükseltmek gibi amaçlarla kullanılan, çevresel etkilere karşı dayanıklılık sağlayacak mekanik özelliklere sahip tekstil ürünleri olarak tanımlanabilir. Bunların yanında tarım tekstilleri; gübre ve su kullanımında azalma sağlamakta, ürünün hasat zamanının ayarlanmasını olanaklı kılmaktadır [8,12,13]. Başlıca tarımsal tekstil ürünleri şunlardır:

- Toprağın nemini koruma, dondan korunma gibi amaçlar için yer örtüleri (mulch),

- Erozyonla mücadele amaciyla kullanilan biyolojik sargilar (bio-rolls),

- Yeşillendirme keçeleri (greening mats),

- Yabani otla mücadele amaçlı kumaşlar (weed protection),

- Çim güçlendirme ve koruma ağları (turf reinforcement/protection nets)

- Kök toplama ağları (root ball net)

- Ürün toplama, paketleme ve taşıma amaçlı tekstiller,
- Tarım fileleri ve plastikleri (agro-nets) $[14,15]$.

Tarım tekstilleri, üretim tekniği bakımından dokuma, örme (çözgülü örme) ve dokusuz yüzey (needle-punched ve spun-bonded) olarak üç temel gruba ayrılabilir [9]. Tarım tekstillerinin üretiminde en çok kullanılan lifler; başta poliolefin (polipropilen) grubu olmak üzere, naylon, poliester, polietilen, jüt ve yün lifleridir [13]. Yün lifi iğneleme tekniği ile dokusuz yüzey haline getirilerek tarımsal yer örtüleri üretiminde kullanılmaktadır. Jüt lifi ise yaygın olarak tarım ürünlerinin paketlenmesinde kullanılan tekstil ürünlerinin üretiminde kullanılmaktadır. Doğal liflerin olumlu özelliği doğada çözünebilir olması iken, olumsuz bir özelliği ömürlerinin kısa olmasidır. Yapay lifler ise, fiyat/performans verimliliği, taşıma ve kurulum kolaylığ için az yer gerektirmesi, dayanıklılık bakımından sahip olduğu üstünlükler nedeniyle tarım tekstillerinin üretiminde doğal liflere göre daha fazla kullanım alanı bulmaktadır $[8,12]$. Tarım tekstillerinden beklenen başlıca özellikler aşağıdaki şekilde sıralanabilir:

- Güneş 1şınlarına (solar radiation) dayanım,

- Morötesi işınlara (UV) dayanım,

- Hava, su, oksijen ve çeşitli iklim şartlarına dayanıklılık,

- Mikro-organizmalara dayanım,

- Doğada çözünürlük (biodegradability),

- Suyu tutma ve buharlaşmayı azaltma,

- Monte edilmeye uygun kararlı bir yapı, hafiflik ve sağlamlık,

- Çeşitli dış etkenlere karşı koruyuculuk,

- Maliyet/performans oranının düşük olması,

- Kolay taşınabilir ve depolanabilir olması,

- Uzun kullanım ömrü $[8,12,13,16]$.

Belli bir amaç için üretilen tarım tekstilinin aynı zamanda başka olumlu veya olumsuz etkileri de olabilmektedir. Bu nedenle tarım tekstillerinin çok işlevli ürünler olduğu söylenebilir. Bu durumda, bir tarım tekstili ürünü tasarlanırken sahip olacağ1 işlevlerin en iyi etkiyi yapacak şekilde dengelenmesi gerekmektedir. 


\subsection{Tarımsal Yer Örtüleri (Mulch)}

Tarımsal örtme (malçlama); bitki köklerini ve toprağı istenmeyen çevresel etkenlerden korumak, toprağın nemini korumak, toprak sicaklığını düzenlemek, süzme yoluyla besin kaybını azaltmak, otla mücadele, meyveyi temiz tutmak, erkenci ve toplam verimde artış sağlamak, kaliteyi arttırmak için toprak yüzeyinin bu amaçla üretilmiş çeşitli malzemeler ile örtülmesi işlemidir. Bu tür örtme amaçlı tekstil malzemeleri "tarımsal yer örtüleri” (mulch) olarak adlandırılmaktadır [17]. $\mathrm{Bu}$ örtüler topraktaki nemi ve 1sıyı korumakta, bitki köklerinin nefes almasını sağlayarak nem ve havaya ulaşmasını kolaylaştırmakta, büyümeyi hızlandırmakta, maliyetleri ve istenmeyen otlarla mücadele için kullanılan kimyasalların tüketimini azaltabilmektedirler. Bunun yanında tarımsal yer örtüleri, bitkinin dikey büyümesine izin verirken meyvenin toprakla temasını engellemek suretiyle çürük ve zedelenmiş ürün oranını azaltmak amacıyla da kullanılmaktadır $[3,18]$.

Tarımsal yer örtü malzemeleri, doğal liflerden (yün, jüt, Hindistan cevizi lifi vb.) veya yapay liflerden (polipropilen) dokusuz yüzey yapısında üretilmektedir [19]. Şekil 3’te çeşitli özelliklerde tarımsal örtülere ve kullanım biçimlerine örnekler verilmiştir.

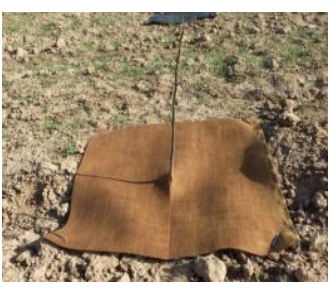

(a)

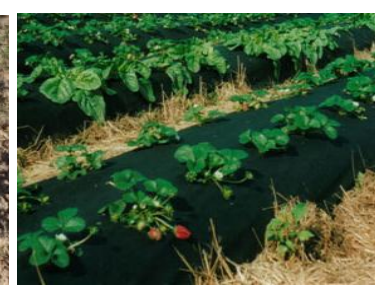

(b)
Şekil 3. Tarımsal yer örtülerine örnekler; (a) Jüt lifinden üretilmiş (b) Polipropilen lifinden üretilmiş, dokusuz yüzey yer örtüsü $[20,21]$.

\subsection{Biyolojik Sargılar}

Biyolojik sargılar (bio-rolls) genellikle, Hindistan cevizi liflerinin sıkıştırılıp yuvarlanması sonucunda elde edilen keçe benzeri yapının, UV katkılı polipropilen ağla desteklenerek sabitlenmesi şeklinde üretilmektedir. Bu dokular özellikle su kenarlarında, toprak kaybını önlemek, bitkiyi su akımından korumak, bitki gelişimini hızlandırmak gibi amaçlarla kullanılmaktadır. Şekil 4'te bu sargıların görünüşü ve kullanımına ilişkin örnekler verilmiştir. Biyolojik sargılar düz bir katman halinde de üretilmekte ve kullanılmaktadır [22].
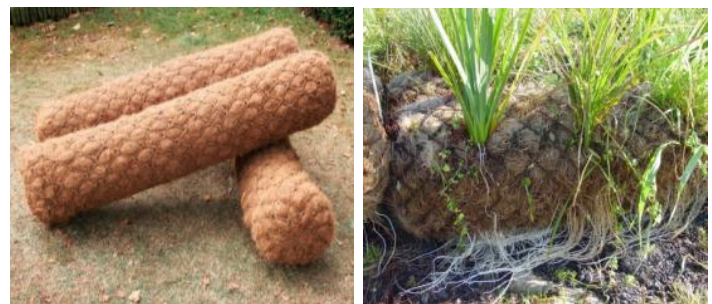

Şekil 4. Biyolojik sargılar ve uygulanmasına örnek $[23,24]$

\subsection{Yeșillendirme Keçeleri}

Yeşillendirme keçeleri çatı, duvar gibi toprak bulunmayan yüzeyleri yeşillendirmek amacı ile bitkinin gelişimine olanak veren keçe şeklinde üretilmiş tekstil malzemeleridir. Bu dokusuz yüzey keçeler genellikle Hindistan cevizi lifinden üretilmekte ve dikiş ile sağlamlaştırılmaktadır. Sağlamlaştırma öncesinde doku içine istenirse tohum da yerleştirilmektedir. Yeşillendirilmek istenen yüzey bu keçe ile kaplanmakta ve bitki gelişimi sağlandığında yeşil bir alan elde edilmektedir [25]. Bitki gelişimi keçenin yüzeye yerleştirilmesi sonrasında sağlanabildiği gibi, önceden bitki gelişimi sağlanmış olan keçelerin istenen yüzeye sonradan yerleştirilmesi de mümkün olabilmektedir (Şekil 5).
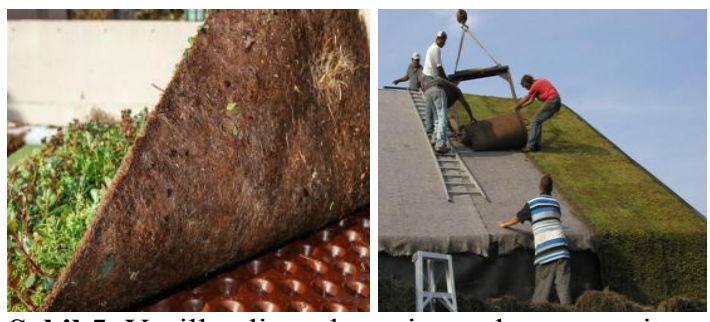

Şekil 5. Yeşillendirme keçesi uygulamasına ait örnekler [26,27] 


\subsection{Zararlı Otla Mücadele Kumaşları}

$\mathrm{Bu}$ tür kumaşlar toprakta doğal olarak büyüyen zararlı otların yetişmesini önlemek için kullanılmaktadır (Şekil 6). Hava geçişine izin veren, nefes alabilen, suyu kolaylıkla geçiren, genellikle iğneleme tekniği ile üretilmiş dokusuz yüzey kumaşlardır. Bu kumaşlar, uzun zincirli poliolefin liflerinden üretilmektedir. Uygulamada çoğunlukla, koyu renkli (siyah, kahverengi, yeşil), UV 1şınlarına dayanıklı (\%70, 500 saat) ve fotosentezi engellemek amacıyla güneş 1şı1nı geçirgenliği azaltılacak şekilde tasarlanmış dokusuz yüzey kumaşlar tercih edilmektedir. Ağırlıklı olarak bahçecilikte ve seracılıkta uygulama alanı bulmaktadır.

Başka bir uygulama şekli de içine ilaç katılmış dokusuz yüzey kumaş kullanarak, yürüyen parazit böceklerin fidelere ve bitkilere yaklaşmasının engellenmesidir $\quad[13,28,29]$. Bu kumaşların polipropilen şerit ipliklerden dokuma yolu ile üretilenleri de mevcuttur.
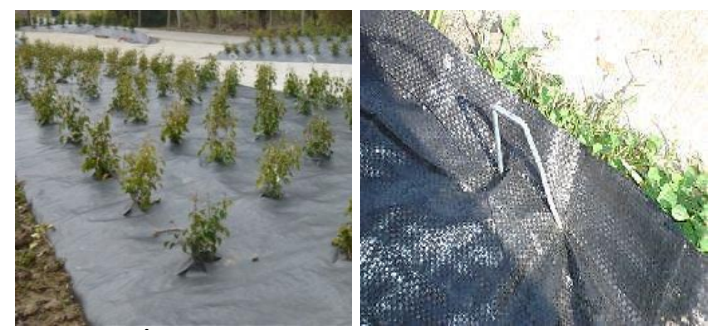

Şekil 6. İstenmeyen otlarla mücadele için kumaş kullanımına örnekler [16,30]

\section{5. Çim Güçlendirme Ăgları}

Çim güçlendirme ağları (turf reinforcement /protection nets), çimlendirmeyi kolaylaştırmak ve düzgün büyümeyi sağlamak amaciyla kullanılmaktadır (Şekil 7). Sağlam yapılı sentetik filamentlerden gözenekli ağlar şeklinde üretilmektedir. Bu ağlar çim köklerinin topraktan kolayca ayrılmasını önleyerek, hızlı ve düzgün şekilde büyümesini sağladığı gibi, üzerinde yayaların ve taşıtların gezinmesi durumunda hasara karşı koruyucu işlevi de görmektedir [16].

\subsection{Kök Koruyucu Ağlar}

Kök koruyucu ağlar (root ball nets), bitkinin kökündeki toprağı bir arada tutarak köklere tutunmasını sağlamakta, taşıma ve depolama sırasında kökleri hasardan korumaktadır (Şekil 8).

Polimer liflerden üretilen ağlar esnek olduğundan, köklerin büyümesi durumunda genişleyebilmekte, gözenekli olması nedeniyle su geçişine izin vermekte, dikim için bekleyen bitkilerin taşınmasını ve depolanmasını kolaylaştırmaktadır. Doğada çözünür malzemelerden (örneğin; doğal lif olarak jüt veya sentetik lif olarak nişasta bazlı doğada çözünür lifler) üretilmesi tercih edilmelidir [16].

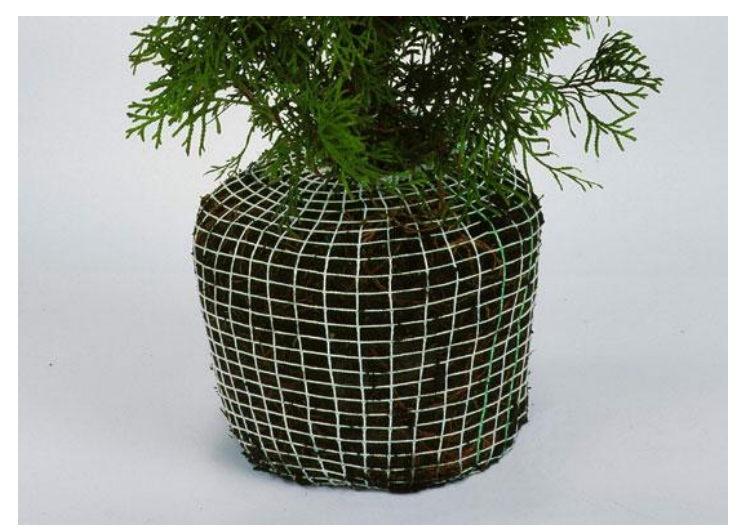

Şekil 8. Kök koruyucu ağın kullanımına bir örnek [16]

\subsection{Hasat Ağları}

Hasat ağları ürünün ağaçtan toplanmasını kolaylaştırmakta, işgücü maliyetini azaltmaktadır. $\mathrm{Bu}$ tür ağlar genel olarak çözgülü örme ve dokuma tekniği ile üretilebilmektedir. Hasat ağlarının ürünü darbeden koruyacak şekilde esnek olması, gözenek ölçülerinin ürüne uyumlu olması, yırtılma direncinin yüksek olması, çevre dostu olması, hava, su ve aside karşı dirençli olması, morötesi (UV) 1şınlara dayanıklı olması, $-30^{\circ} \mathrm{C}$ ile $+70^{\circ} \mathrm{C}$ aralığındaki hava sıcaklığına dayanması, fiyatının işgücü maliyetini düşürmeye izin vermesi gerekmektedir. Şekil 9'da zeytin toplamak 
amacıyla kullanılan hasat ağlarına bir örnek verilmiştir. \%100 PP'den dokuma yöntemi ile 100 $\mathrm{g} / \mathrm{m}^{2}$ ağırlığında, $4 \times 6 \mathrm{~m}$ ve $6 \times 14 \mathrm{~m}$ boyutlarında üretilebilen zeytin toplama ağları, toplama süresini azaltmakta, hasat sirasında kayıpları en aza indirmekte ve işçilik maliyetlerini düşürmektedir [16,19].

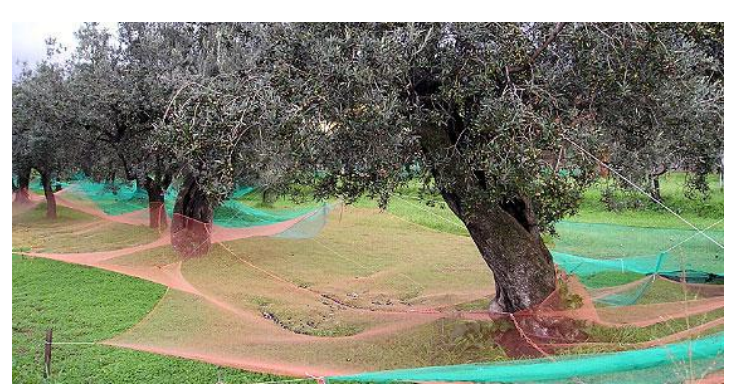

Şekil 9. Hasat ağlarının zeytin toplamada kullanımı [16]

\section{8. Ürün Taşıma Ağları}

Hasat edilen sebze ve meyvelerin pazara sunulmak üzere paketlenmesi, taşınması veya depolanması sırasında çeşitli tarımsal ağlar kullanılmaktadır. Bu ağlar genellikle yüksek dayanımlı polipropilen liflerden üretilmektedir. Bazı ağlar, ürünü standart ölçülerde paketlemek için (Şekil 10a) kullanılırken, bazı ağlar ürün paketlerini paletler üzerine sabitlemek için (Şekil 10b) kullanılmaktadır [16]. Bunun yanı sıra, gübrelerin ve tarımsal ürünlerin taşınması için kullanılan küçük jüt, kağıt veya plastik torbalar yerine, bugün birkaç tona kadar varan miktardaki ürünleri taşıyabilecek yapıdaki dokunmuş polipropilen torbalar (big bags) kullanılmaktadır [31].

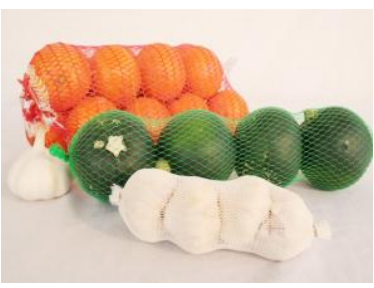

(a)

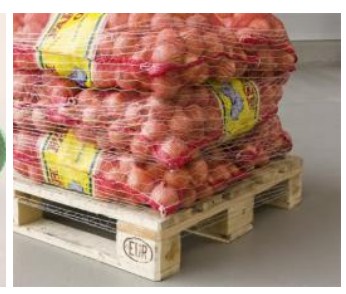

(b)
Şekil 10. Ürün taşıma ağlarının (a) paketleme (b) palete sabitleme şeklinde kullanımı
Ürün taşıma ağları arasında sayılabilecek diğer bir tarımsal tekstil ürünü de balya koruma ağlarıdır. $\mathrm{Bu}$ ağlar (Şekil 11), balyaları sarmak suretiyle ürün kaybını azaltmakta ve olumsuz hava koşullarında (kuvvetli rüzgâr) ürünü korumaktadır. Düzenli gözenek açıklıklarına sahip bu örtüler sayesinde balya besleme problemleri ve hasat sırasında ürün kayıpları en aza indirilmektedir [19].

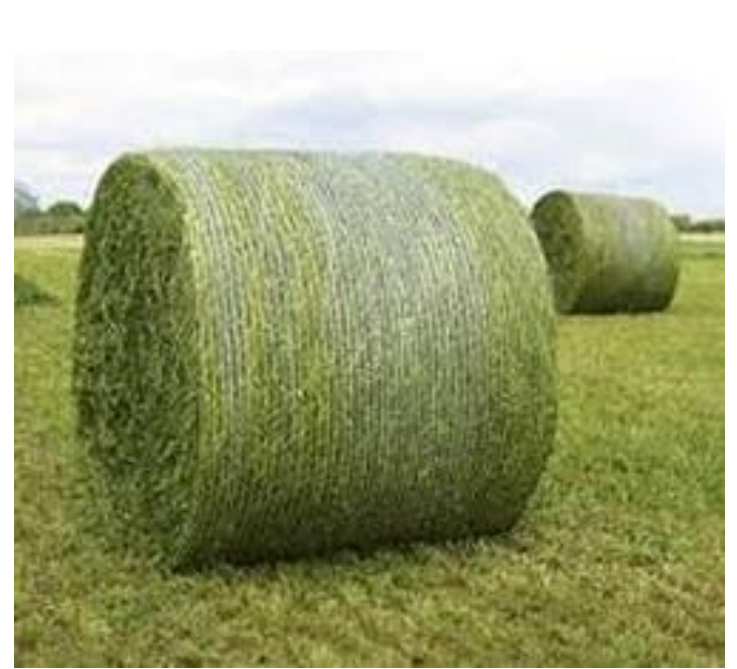

Şekil 11. Balya koruma ağları

\subsection{Dış Etkenlerden Koruma Amaçlı Kullanılan Tarım Tekstilleri}

Koruma amaçlı kullanılan tarım fileleri; ürünü dondan, doludan, kardan, şiddetli yağmurdan, kuşlardan, böceklerden korumak, güneş ışınlarının etkisini azaltmak, gölgeleme yapmak, mikro-klima oluşturmak, toprağı örtmek, ürünü taşımak, ürün hasadını kolaylaştırmak ve hasarı azaltmak vb. amaçlar için kullanılmaktadır. Gelecekte, hasat öncesi ve sonrası için yeni kullanım amaçlarına dönük tarım tekstillerinin geliştirilmesi beklenmektedir [18]. Tarım tekstillerinin kullanımının yaygınlaşmasında maliyet unsuru önemli bir etken olmaktadır. Kalite ve verimlilik artışı sağlamasının yanı sıra sigorta giderlerinin de yükselmesi $\mathrm{AB}$ ve Amerika ülkelerinde seçenek olarak tarım filelerinin kullanımını hızla arttırmaktadır. $\mathrm{Bu}$ konuyu inceleyen birçok araştırma yapılmıştır [32]. 


\subsubsection{Meteorolojik Etkenlerden Koruyucu Fileler}

Meteorolojik etkenlerden koruyucu tarımsal fileler çoğunlukla rüzgâr, dolu ve yağmurun bitkiye ve/veya ürüne zarar vermesini engellemek amacıyla kullanılmaktadır. Bu fileler herhangi bir etkene karşı koruma amacıyla kullanılırken, aynı zamanda başka etkenlere karşı kısmen de olsa koruma görevi yapabilmektedir. Bu yüzden çok işlevli oldukları söylenebilir.

Rüzgâr kırıc1 ağlar (anti-wind nets), rüzgârın hareketinden kaynaklanan mekanik zararları (dal kırılması, çiçek dökülmesi, yaprak kuruması ve yırtılması vb.), biyolojik sorunları (yüksek terleme/buharlaşma ve tozlaşmada zorluk), meyve berelenmelerini ve aşırı sıcaktan kavrulmayı azaltmak amaçlı kullanılmaktadır (Şekil 12a). Bu fileler bazı durumlarda rüzgâr hızını keserek meyve sıcaklığını artırabilmekte, rüzgâr kaynaklı toprak erozyonunu da azaltabilmektedir. Bununla birlikte ürünü toz, tuz ve kumdan koruyarak kalite artışı sağlamakta ve tarımsal yapılar üzerindeki rüzgâr yükünü azaltmaktadır. Rüzgâr kırıcı fileler çoğunlukla UV ışınlarına karşı dayanım kazandırılmıs polietilen monofilament ipliklerden dokuma ve örme teknikleriyle üretilmektedir. UV dayanımı malzemenin ömrünü kayda değer ölçüde artırmaktadır. Rüzgâr kırıcı ağlar çelik, beton veya ağaçtan yapılmış, kolonlar veya kafes kirișlerinden oluşan sabitlenmiş destek yapı elemanlarına monte edilirler. Bazı üreticiler arazi kenarlarına dikilmiş ağaçlara da tutturabilmektedir. Ağın rüzgâr azaltma yeteneği; yapının yüksekliğine, ağın gözenek büyüklüğüne ve çitin bitkilere uzaklığına bağlıdır [3,18].

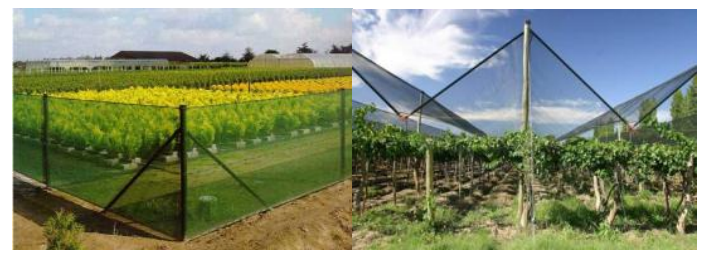

(a)

Şekil 12. (a) Rüzgâr kırıcı ve (b) doludan koruyucu filelerin kullanımına örnekler [33]
Dolu fileleri (anti-hail nets), bitki ve ürünlerin doludan zarar görmesini önlemek için kullanılmaktadır (Şekil 12b). Yaygın olarak; üzüm, kayısı, kiraz gibi meyvelerin yetiştiriciliğinde, açık alanlarda uygulanmaktadır. Genellikle, dolu ve yağmurdan koruma işlevleri birlikte kullanılmaktadır. Yağmurdan koruma, çiçekler ve kabuksuz meyveler için gerekli olmakta, ızgara biçiminde tasarlanarak aşırı yağmur etkisini azaltmaktadır. Dolu fileleri aynı zamanda güneşin ışınım etkisini ve iç sıcaklığı azaltıcı yönde işlev görmektedir.

Dolu fileleri; hafif, sağlam, yırtılma direnci yüksek, UV ışıllarına dayanıklı olarak üretilmekte olup temel işlevlerinin yanı sıra rüzgâr ve kuşlara karşı koruma görevi de yapmaktadır. Bu fileler genellikle UV ışınlarına karşı dayanım kazandırılmış polietilen monofilament ipliklerden dokuma ve örme teknikleriyle üretilmektedir. Fileler, özel destek yapılarına veya doğrudan bitkinin kendisine monte edilmektedir. Bazı montaj biçimlerinde; file, mevsim ve meteorolojik şartlara bağlı olarak gölgeleme etkisini ayarlayabilmek için destek yapısı boyunca hareket ettirilebilmektedir. Filelerin montaj şekli; tarım uygulaması türüne göre değişebilmekte, filelerin gerginliği için kablolar ile destek sağlanabilmekte, dolunun düşmesini sağlamak için \%50-60 eğimli uygulamalar yapilabilmektedir $[18,8]$.

\subsubsection{Gölgeleme Fileleri}

Gölgeleme fileleri (shade nets), süs bitkileri gibi gölgeyi seven tarım ürünleri yetiştiriciliğinde seranın içindeki sıcaklığı düşürebilmek için güneşin ışınım etkisini (UV) azaltmak ve içeride bir mikro-klima etkisi yaratmak amaciyla kullanılmaktadır (Şekil 13). Bu amaçla kullanılan fileler dokuma veya örme tekniği ile üretilmektedir. Dokuma fileler genellikle UV katk1l $\% 100$ polipropilen (PP) monofilament ipliklerden üretilmektedir. $\mathrm{Bu}$ ağlar rüzgârdan koruma, görünmeyi engelleyici perde gibi farklı amaçlar için de kullanılabilmektedir. Örme kumaşlar ise UV katkılı \%100 polietilen (PE) monofilament ipliklerden üretilmektedir. $\mathrm{Bu}$ filelerin özgün yanı kilit ilmek yapısı nedeniyle 
sökülmeksizin makasla kesilerek şekillendirilmeye uygun olmasıdır. Gölgeleme fileleri farklı renklerde ve değişik kesitli ipliklerden üretilebilmektedir. Kullanılan file renginin tarımsal üretimin niteliği ve niceliği üzerinde etkilerinin bulunduğu birçok çalışma ile gösterilmiştir.

File sisteminin verimliliği, filenin "gölgeleme faktörüne" bağlıdır. Bu fileler güneş 1şınlarını \%90'a kadar farklı oranlarda engelleyecek şekilde üretilmektedir. Gölgeleme fileleri, güneşli günlerde hasat süresini uzatmak amacıyla da kullanılmaktadır. Örneğin; Güney İtalya'da çeri (cherry) cinsi domates hasatı normalde Haziranda yapilırken, hasat Ağustosa kadar geciktirilebilmektedir. Gölgeleme fileleri virüssüz üretim yapılan seralarda da kullanılmaktadır. Ancak, içerideki nem oranındaki artış ve hava akışının azalması bu şekilde kullanımını sınırlamaktadır. Fileler, özellikle soğuk kış gecelerinde, seranın içinde taşınım ve 1 şınım yoluyla oluşan 1sı kaybını önlemek için 1sı perdesi olarak da kullanılmaktadır. Bu tür uygulamalarda genellikle seranın içinden yayılan 1sı 1şınımını yansitabilen alüminyum renkli ağlar tercih edilmektedir. Seralardaki gölgeleme file sistemleri genellikle çelik destek elemanları kullanılarak kavisli veya düz çatı şeklinde tasarlanmaktadır. Isı perdeleri seranın içinde ray üzerinde hareket edebilecek şekilde monte edilmekte ve genellikle oluk seviyesine yerleştirilmektedir $[8,18]$.

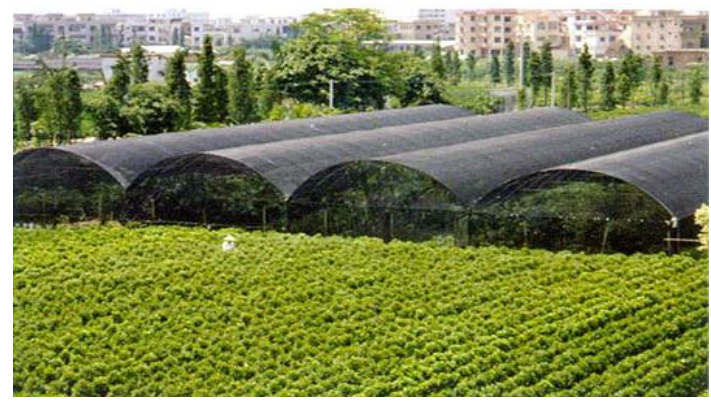

Şekil 13. Gölgeleme filelerinin uygulanmasına bir örnek

\subsubsection{Böceklerden Koruyucu Fileler}

Beyazsinek (bemisia tabaci) gibi canlılar bitkiye ulaştıklarında, taşıyıcı olduklarından mantar ve virüs çoğalmasına dolayısıyla hastalık oluşumuna neden olmaktadırlar. Böcekten koruyucu fileler (anti-insect nets) bu tür canlıları bitkilerden uzak tutmak, tarım ilacı kullanımını azaltmak, çevre ve insan sağlı̆̆ını korumak amaciyla tarım ilaçlarına bir seçenek olarak düşünülmekte ve çoğunlukla organik tarımda kullanılmaktadır (Şekil 14). Bu fileler, tek veya çift kat olarak kullanılabilmektedir. Yeni bir gelişme; filenin renk etkisi ile (özellikle sarı) zararlıları kendine çekmesi ve canlıların file üzerine uygulanmış olan kimyasala yapışarak ölmesinin sağlanmasıdır. Yapılan çalışmalar, renk spektrumunun mavi/ultraviyole ve sarı kısımlarının beyazsinekler için çekici olduğunu ortaya koymuştur.

Beyazsinek zararlısına karşı kullanılan fileler, böcekleri uzaklaştırmak/etkisiz hale getirmek için alphacypermethrin, pyrethroid gibi baz1 kimyasallar veya yapışkan maddeler ile muamele edilmektedir. Zararlılar, çekici olan renklerin etkisi ile file üzerinde toplanmakta ve fileye uygulanmış olan yapışkan maddeye yapışmaları sağlanarak etkisiz hale getirilmektedir. Yapışkan madde yerine zararlıları öldüren kimyasal maddeler de kullanılabilmektedir. Kullanılan bazı kimyasallar ise zararliya biyolojik olarak uzaklaştırıcı etki yapmaktadır. Literatürde, bazı renklerin böcekleri uzaklaştırma etkisinden de söz edilmektedir [8,34,35,36].

Bunun yanında bu tür fileler, seralarda tozlanmaya yardımcı olan yaban arıları gibi tozlayıc1 böceklerin kaçmasını önlemek amacıyla da kullanılmaktadır. $\mathrm{Bu}$ filelerde gözenek büyüklügü ve rengi (böcekleri iten veya çeken renkler) en önemli faktörlerdir. Fileler küçük gözenekli ve az geçirgen bir yapıya sahip olmaktadırlar. Güneşin ışınım etkisini azaltmak için beyaz veya saydam fileler kullanılmaktadır. Ancak bunun, hava akışında azalma ve bağıl nemin artması şeklinde negatif etkileri de olmaktadır. Bu kumaşlar çoğunlukla PE veya PP monofilamentlerden dokuma yöntemiyle, 0,0075 inch gözenek boyutlarında üretilmektedir [3,18,28]. 


\subsubsection{Küçük Hayvanlardan Koruyucu Fileler}

Yaygın olarak "kuş fileleri" olarak da adlandırılan bu tür koruyucu fileler, tarım ürünlerine zarar verebilen kuş, tavşan, sincap, fare gibi küçük hayvanlardan korunmak amaciyla sera havalandırmalarında veya doğrudan ağaçların üzerinde kullanılmaktadır (Şekil 15). Bu fileler genellikle HDPE (High-density polyethylene) monofilament ipliklerden örme tekniğiyle üretilmekte ve göze büyüklüğü korunma sağlanacak canlı türüne göre seçilmektedir. Örneğin, kuşlardan korunma amaçlı kullanılan ağların göze boyutları 48 x $48 \mathrm{~mm}$ veya 100 x 100 $\mathrm{mm}$ olarak tercih edilmektedir $[8,18,19]$.

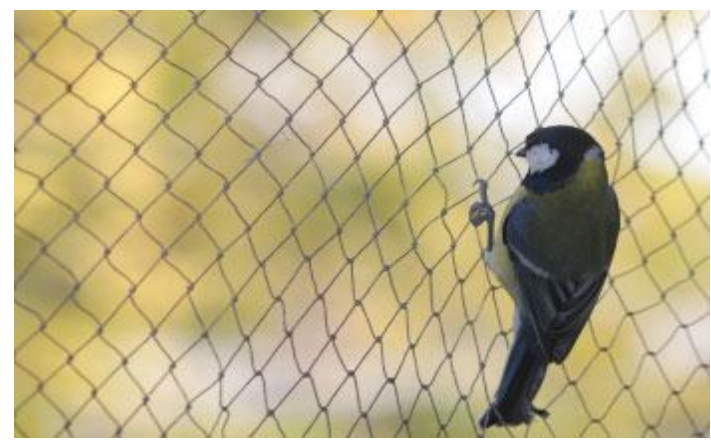

Şekil 15. Kuşlar için koruyucu file kullanımına bir örnek

\subsubsection{Isı Tutucu Kumaşlar}

İklimin sert olduğu bölgelerde tarım ürününü soğuk ve dondan korumak amaciyla çoğunlukla dokusuz yüzey tekstil ürünleri kullanılmaktadır (Şekil 16). Bu kumaşlar aynı zamanda ürünü böceklerden ve diğer olumsuz dış etkilerden de korumaktadır. Isı tutucu kumaşlar, güneşli zamanlarda 1sıyı içeriye hapsetmekte, gece soğuk zamanlarda ise topraktan yayılan 1sıyı içeride tutmaktadır. Özellikle, beklenmeyen zamanlardaki öldürücü soğuk ve don etkilerine karşı bitkiyi koruyabilmektedirler. Bunun yanında 1sitmada \%40'a kadar enerji tasarrufu sağlanması da mümkündür. Plastik örtülerden (membran) farklı olarak bu kumaşlar bitkinin üzerine doğrudan yayılabilmektedir. Plastik örtüler donu kendine çekmekte ve bitkiye temas ettiğinde yaprağın soğuktan yanmasına neden olmaktadır. Dokuma yoluyla üretilmiş 1 ș tutucu kumaşlar, güneş 1şığı, hava ve suyun bitkiye ulaşmasına daha çok izin vermektedir $[8,18]$.

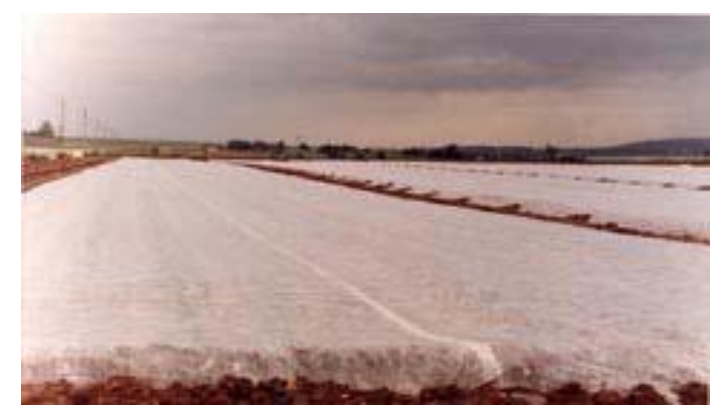

Şekil 16. Isı tutucu kumaş uygulamasına bir örnek [8].

\subsection{Biyolojik Engelleyiciler}

Biyolojik engelleyiciler olarak adlandırılabilecek tekstil malzemeleri; toprağın altında bitki köklerini büyüme sırasında yönlendirmek, bina temelleri veya çeşitli peyzaj yapılarını bitki köklerinin zararlı etkilerinden korumak, farklı bitki köklerini dengeli beslenmeleri için veya hastalık bulaşmasına karşı birbirinden ayırmak gibi amaçlar için kullanılmaktadır [8]. Şekil 17'de bir binayı ağaç köklerine karşı korumak için biyolojik engelleyicinin nasıl kullanılacağı gösterilmektedir. $\mathrm{Bu}$ tür ürünler; köklerin ilerlemesine karş1 dayanıklı, düşük ağırlıklı ve kurulumu kolay, toprak kimyasallarına, küf ve böceklere karş1 dayanıklı ve \%100 geri dönüşüm özelliklerine sahip olarak üretilmektedir [19].

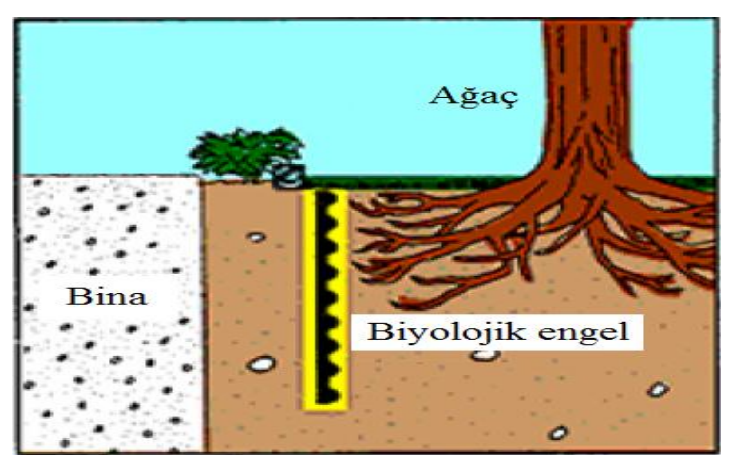

Şekil 17. Biyolojik engelleyici kullanımına ilişkin bir örnek [8] 


\subsection{Balık Ağları}

Balık ağları, balıkçılıkta kullanılmak üzere çözgülü örme tekniği ile poliamid veya yüksek yoğunluklu polietilen (HDPE) monofilament ipliklerden (200-1500 dtex) üretilmektedirler. Balık ağlarının iplik kesişme noktalarında düğüm yoktur ve bu önemli bir avantaj oluşturmaktadır. $\mathrm{Bu}$ avantaj sayesinde ortalama ömrü 2-3 y1l olan balık ağlarının kullanım ömrü, bazı balıkçılar tarafından onarılmak suretiyle arttırılabilmektedir [16,37].

\section{TARIM TEKSTILLERINDE YENILIIKLER}

Son yıllarda, tarım tekstilleri alanında göze çarpan başlıca yenilikler arasında; tarım tekstili üretiminde nanoteknolojinin ve doğada çözünür polimerlerin kullanımı sayılabilir. Nanoteknolojinin kullanımına bir örnek olarak; bitkilerin nanoliflerden oluşmuş bir tülbent ile kaplanması yoluyla zararlı kimyasallardan ve böceklerden korunması verilebilir. Aynı zamanda nanoliflerden oluşmuş bu katmanın zamanla gübre salgılayarak bitkiyi beslemesi de mümkün olabilmektedir. Bu uygulamayı temsil eden bir örnek Şekil 18'de verilmiştir [38]. Buna benzer uygulamaların gelecekte çoğalması ve nanoteknolojinin tarım tekstillerine birçok yenilik getirmesi kaçınılmaz görünmektedir.

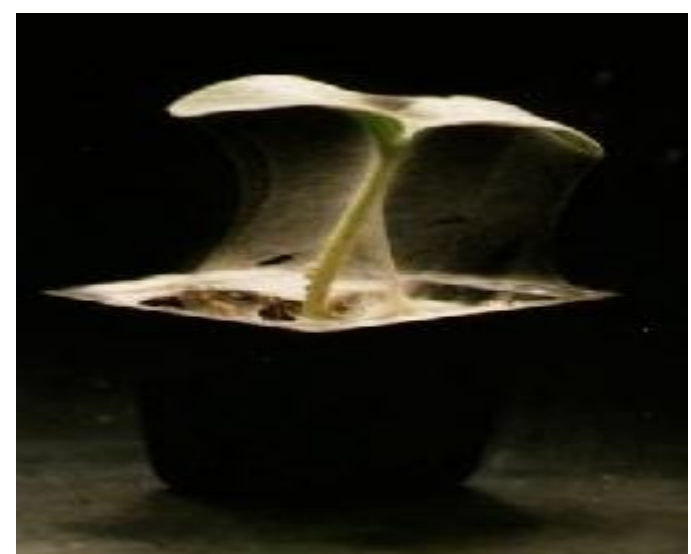

Şekil 18. Nanolif katmanıyla kaplanmış bir bitki [38]
Doğada çözünür polimerler; doğal ortamdaki bakteriler, mantarlar gibi mikro canlıların faaliyetleri ile çözünebilen ve ekolojik döngüye herhangi bir olumsuz etki yapmayan maddelerdir. $\mathrm{Bu}$ tür polimerlerden üretilmiş malzemeler; geri dönüşümsüz atıkları azaltması, kaynakları koruması, çevre kirliliğini azaltması, iş gücü ve atık maliyetlerini düşürmesi yönüyle tercih edilmektedir. $\mathrm{Bu}$ tür polimerlerin tarım tekstillerinde kullanımı bir "niş" pazar olarak görülmeye başlanmıştır. Doğada çözünür polimerlerden üretilmiş çeşitli tarım tekstili ürünleri ticari olarak piyasada bulunmaktadır. Polylactic acid (PLA) ve polyhydroxyalkanoate (PHA) polimerlerinin bu anlamda gelecekte önemli paya sahip olacağı belirtilmektedir. Bununla birlikte doğada çözünür polimerlerin özellikle tarım tekstillerinden beklenen teknik özellikler ve maliyet düzeyi açısından istenen düzeye gelmesi kullanımının yaygınlaşması açısından önem taşımaktadır. Literatürde, bu konuya ilişkin batı ülkelerinde yapılan çeşitli projelere rastlanmıştır [39,40,41,42].

\section{TARIM FILELERININ EKOLOJIK AÇIDAN DEĞERLENDİRMESI}

Tarım tekstilleri, özellikle sentetik polimerlerden üretilenler, ekolojik açıdan olumsuz etkileri nedeniyle sorgulanmalıdır. $\mathrm{Bu}$ etkiler; filelerin üretim sürecinde ve kullanım sonrası atık olarak doğal yaşama yapacağı olumsuz etkiler, geri dönüşüm sorunları ve kullanım sırasında canlıların yaşam döngüsüne yapacağı olası etkiler olarak sıralanabilir. Çoğunlukla yapay liflerden üretilmiş olan tarım tekstilleri işlevini tamamladıktan sonra yüksek miktarda atık oluşturmaktadır. Bu atıklar geri dönüşüme girmediği veya doğada çözünür olmadığı takdirde doğal ortamda çok uzun süreler kalmakta ve çevre kirliliği yaratmaktadır. Tarım tekstillerinin kullanım sırasında da doğal yaşam döngüsüne etkisi olabilecektir. Bu nedenle, tarım tekstillerinin kullanımının yaygınlaşmasının orta ve uzun vadede doğa üzerindeki etkilerinin ve etki düzeylerinin araştırılması zorunlu görülmektedir. Süreç içinde ortaya çıkan çevre sorunlarının, olası 
teknolojik gelişmelerle azaltılabilmesi de mümkün olabilecektir.

Tarım tekstillerinin olumsuz etkilerinin yanı sıra, tarımsal üretim miktarını ve ürün kalitesini artırıcı, tarım ilacı, enerji ve su tüketimini azaltıcı yönde etkisinin olması ekolojik açıdan önemli kazanımlardır. $\mathrm{Bu}$ nedenle, tarım tekstillerinin tarımsal üretimi destekleyecek ama ekolojik dengeyi de gözetecek şekilde tasarımı, üretilmesi, bilinçli ve sistemli olarak kullanılmasının mümkün olduğu öngörülebilir. Bu konuya önem verilmesi ve daha fazla bilimsel araştırmanın yapılması gerekli görülmektedir [3,42,43].

Tarım tekstillerinin çevre dostu olarak üretimi ve kullanımına katkı sağlayacak gelişmelerden bir tanesi, doğada çözünür (biodegradable) polimerlerin kullanılmasıdır. Bu tür polimerlerin geliş̧irilmesi ve kullanılmasının teşvik edilmesi, bu konuda yapılan çalışmaların artırılması gerekmektedir. Böylece, doğada çözünür polimerlerin teknik özelliklerinin geliştirilmesi (özellikle kullanım ömrü) ve maliyetlerinin düşürülmesi yönünde yapılacak bilimsel çalışmalar önem kazanmaktadır. Doğada çözünür polimerler konusunda dünyada yoğun çalışmalar yapılmakta olup geleneksel tarım tekstillerinin sağladığı özellikleri sağladığı öne sürülen, bitkilerden elde edilmiş doğada çözünür polimerlerden üretilen tarım tekstillerinin dünya pazarlarında yer almaya başladığı da gözlenmektedir. Bunun yanında, ülke çapında tarım tekstilleri satışının kontrollü yapılması ve geri toplanmasının güvence altına alınması (Avrupa'da uygulanan Yeşil Nokta sistemine benzer şekilde) için belgelendirme sistemi oluşturulması önerilebilir [12,40,44].

\section{SONUÇ}

Dünyada tarımsal üretimin gelecek yıllarda daha fazla değer kazanacağı ve stratejik öneminin artacağı öngörülmektedir. Tarımın kısıtları arasında olan su kıtlığı, tarımsal hastalıklar, ekolojik üretimin öneminin artması ve zorlukları, tarım ürünlerinde nicelik ve nitelik artışının gerekliliği, küresel iklim sorunlarının tarım üzerindeki olumsuz etkileri tarım tekstillerinin kullanımını gündeme getirmiştir. Tarımın ülkemiz açısından önemi, potansiyeli ve kısıtları göz önüne alındığında, tarım tekstillerine ülkemizde de yüksek düzeyde önem verilmesi gerektiği düşünülmektedir.

Tarım tekstillerinin çok çeşitli uygulamalarının bulunduğu, gelecekte yeni uygulama alanlarının ortaya çıkabileceği ve genellikle bir malzemenin birden çok işleve sahip olabildiği anlaşılmaktadır.

$\mathrm{Bu}$ bağlamda, bölgesel çevre koşullarına uygun tarım tekstillerinin tasarımı, üretimi ve seçiminin gerekebileceği düşünülmektedir. Tarım tekstillerine ilişkin standartlaşmanın yeterli düzeyde olmadığ 1 ve kalite kontrol test yöntemleri konusunda belirsizliklerin devam ettiği belirlenmiştir. Balık ağları konusunda çok sayıda uluslararası standarda rastlanırken, diğer tarım tekstilleri ile ilgili çok az standardın bulunduğu gözlenmiştir.

Nanoteknolojinin ve doğada çözünür polimerlerin tarım tekstillerinin geleceğinde önemli rol oynayabileceği saptanmıştır. Bunun sonucu olarak, tarım tekstillerinin de ileri teknoloji ve yenilikçilik anlamında daha fazla önem kazanacağ 1 öngörülebilir. Gittikçe önem kazanan ekolojik yaklaşımın, tarım tekstilleri üretimi ve kullanımını da etkilemesi kaçınılmaz görünmektedir. $\mathrm{Bu}$ bağlamda; ülkemiz için stratejik önemi olan tarım ve tekstil sektörlerinin kesişiminde yer alan tarım tekstilleri alanında, özellikle ülkemiz adına daha fazla bilimsel çalışma yapılması gerektiği sonucuna varılmıştır.

\section{KAYNAKLAR}

1. İncikarakaya, S.Ü., Beyaz, K.B., Rezaei, F., 2015. Doğal Kaynaklar ve Tarım, Türk Bilimsel Derlemeler Dergisi, 6(1), 104-109, 2013.

2. İleri, M.S., Türkiye Tarım Makinaları Sektörü Sektör Raporu, http://www.tarmakbir.org/tr/raporlar.html (20.12.2014)

3. http://www.fibre2fashion.com/industryarticle/textile-industry-articles/agro-textiles-a- 
rising-wave/agro-textiles-a-rising-wave 1 .asp (18.02.2104)

4. http://www.researchandmarkets.com/research/j 62hp8/global_technical (14.03.2015)

5. http://www.emslandgroup.de/files/promotion_emsize_e18_in_melli and_iii.pdf (14.03.2015)

6. Tecnical Textiles and Nonwovens: World Market Forecasts To 2010, David Rigby Associates http://davidrigbyassociates.co.uk/drahtml/techn icaltextilesarticles.html (25.02.2104)

7. http://www.transparencymarketresearch.com/pr essrelease/technical-textiles-market.htm (14.03.2015)

8. Chakrabarti, R., Gowri, K., Kumar, R.S., Agro Textiles-A Review http://www.fibre2fashion.com/industryarticle/32/3158/agro-textiles-a-review1.asp (07.02.2015)

9. Study on Developing Measures to Promote The Use of Agrotextiles in India Under the Technology Mission on Technical Textiles (TMTT), Office of the Textile Commissioner Ministry of Textiles Government of India, 2013.

http://technotex.gov.in/Agrotextiles/Study\%20 on $\% 20$ Developing\%20Measures $\% 20$ to $\% 20$ Pro mote $\% 20$ Use $\% 20$ of $\% 20$ Agrotextiles $\% 20$ in $\% 2$ OIndia.pdf (14.03.2015)

10. Arslan, K., 2009. Teknik Tekstiller, Araştırma Raporları, Müstakil Sanayici ve İşadamları Derneği.

11. Scarascia, G., Sica, M.C., Russo, G., 2011. Plastic Materials in European Agriculture: Actual Use and Perspectives, Journal of Agricultural Engineering, 3, 15-28.

12. Jaiswal, H., Barhanpurkar, S., Chandak, S., Kabra, N., Textile at Agriculture Application, http://www.technicaltextile.net/articles/ (01.03. 2014)

13. Subramaniam, V., Poongodi, G.R., Veena Sindhuja, V., 2008. Agro-Textiles, Man-made Textiles in India, 51(3), 80-84.

http://fzfz.nbdl.gov.cn:81/files/20130709/1373 362058826_0.pdf (15.07.2014)

14. http://www.indiantextilejournal.com/articles/F Adetails.asp?id=1999 (24.02.2014)
15. Pillai, M.S., Vasudev, R., 2001. Applications of Coir in Agricultural Textiles, International Seminar on Technical Textiles, India.

16. http://technotex.gov.in/Agrotextiles/Handbook \%20for\%20Agrotextiles.pdf (20.12.2014)

17. Ekinci, M., Dursun, A., 2006. Sebze Yetiştiriciliğinde Malç Kullanımı, DERİM, Batı Akdeniz Tarımsal Araştırma Enstitüsü, 23(1), 20-27.

18. Castellano, S., Mugnozza, G.S., Russo, G., Briassoulis, D., Mistriotis, A., Hemming, S., Waaijenberg, D., 2008. Plastic Nets in Agriculture: A General Review of Types and Applications, Applied Engineering in Agriculture, 24(6), 799-808.

19. Çetiner, S., 2013. Tarım Teknik Tekstilleri (Agrotech), Teknik Tekstil 2013, Frankfurt Fuarı, Butekom Teknolojik Değerlendirme Raporu, 13-18.

20. http://www.sustaffor.eu/?page_id=204 (20.12.2014)

21. http://www.harshpolyfabric.com/non-wovenfabric-for-mulching-1323113.html (20.12.2014)

22. http://www.green-tech.co.uk/ (20.12.2014)

23. http://www.aquaticengineering.co.uk/aquaticconsultancy/bioengineering (20.12.2014)

24. http://www.brettvalley.com/mulchcomposts.html (20.12.2014)

25. The Complete Book on Jute \& Coir Products (with Cultivation \& Processing), NIIR Board of Consultants \& Engineers, ISBN: 9789381039625, 2014.

http://www.niir.org/books/book/completebook-on-jute-coir-products-with-cultivationprocessing/isbn9789381039625/zb,,18b91,a,37,0,3e8/index.ht $\mathrm{ml}$ (14.03.2015)

26. http://www.hrt.msu.edu/greenroof/researchprojects/plant-evaluations.html (20.12.2014)

27. http://catalystcentre.uoguelph.ca/pages/catalyst -centre-news/greening-the-roof-over-yourhead-a-look-inside-a-growing-industry (20.12.2014)

28. Gemci, R., Tarım Teknik Tekstilleri (Agrotech), Teknik Tekstil 2011. Frankfurt Fuarı, Butekom Teknolojik Değerlendirme Raporu, 14-19, 2011. 
29. http://www.geosynthetics.com/pdf/BioBarrier/SpecificationWeed-Control.pdf (01.05.2015)

30. http://www.beaulieutechnicaltextiles.com/en/ca tegory/c/2/agrotextiles/s/3/weed-control (21.12.2014)

31. Mecit, D., Ilgaz, S., Duran, D., Başal, G., Gülümser, T., Tarakçıoğlu, I., 2007. Teknik Tekstiller ve Kullanım Alanları (Bölüm 2), Tekstil ve Konfeksiyon Dergisi, 17(3), 154160.

32. Iglesias, I., Alegre, S., 2006. The Effect of Anti-hail Nets on Fruit Protection, Radiation, Temperature, Quality and Profitability of 'Mondial Gala'Apples, Journal of Applied Horticulture, 8(2), 91-100.

33. http://www.netco-bv.nl/en/agriculture.html (14.03.2015)

34. Regev, A., Moisa, S., Kiriati, Y., Israel's Agriculture, The Israel Export\&International Cooperation Institute, Ministry of Agriculture \& Rural Development http://www.moag.gov.il/agri/files/Israel's_Agri culture_Booklet.pdf (15.07.2014)

35. Bird, J., Maramorosch, K., 1975. Tropical Diseases of Legumes, Academic Press Inc. Ltd., New York.

36. Martin, T. ve ark., 2014. Repellent Effect of Alphacypermethrin-Treated Netting Against Bemisia tabaci (Hemiptera: Aleyrodidae), Journal of Economic Entomology, 107(2), 684690 ,

37. Paul, P., Gon, D., 2011. Warp Knitted Structures for Technical Use, Journal of the Textile Association, 72/1, 9-21.

38. Çakmak, S., 2011. Elektroeğrilmiş Nanofiberlerin Uygulama Alanları, Nanobülten, 14, 12-21,

http://www.nanott.hacettepe.edu.tr/nanobulten.htm $1(14.02 .2015)$

39. http://cru.cahe.wsu.edu/CEPublications/FS103 E/FS103E.pdf (14.03.2015)

40. http://cordis.europa.eu/project/rcn/89311_en.ht $\mathrm{ml}(14.03 .2015)$

41. http://cahnrs.wsu.edu/newsrelease/2010/04/07/biodegradable-mulchproject-applies-textile-science-to-agriculture/ (14.03.2015)
42. http://www.extension.org/pages/67951/currentand-future-prospects-for-biodegradable-plasticmulch-in-certified-organic-productionsystems\#.VQQx7tLked4 (14.03.2015)

43. Jaiswall, H., Barhanpurkar, S., Chandak, S., Kabra, N., 2012. Textile at Agriculture Application.

http://www.technicaltextile.net/articles/agrotextiles/detail.aspx ?articleid $=4276$ (20.12.2014)

44. http://www.beaulieutechnicaltextiles.com/webs ites/1/uploads/file/Okolys/Okolys\%20Leaflet\% 20EN_LR.pdf (14.03.2015) 
